\title{
Dachsous encodes a member of the cadherin superfamily that controls imaginal disc morphogenesis in Drosophila
}

\author{
Hilary F. Clark, ${ }^{1,3,5}$ Doris Brentrup, ${ }^{2,5}$ Kay Schneitz, ${ }^{2,4}$ Allan Bieber, ${ }^{3}$ Corey Goodman, ${ }^{1}$ \\ and Markus Noll ${ }^{2,6}$ \\ ${ }^{1}$ Howard Hughes Medical Institute, Department of Molecular and Cell Biology, University of California, Berkeley, \\ California $94720 \mathrm{USA}^{2}{ }^{2}$ Institute for Molecular Biology II, University of Zurich, CH-8057 Zurich, Switzerland; ${ }^{3}$ Department \\ of Biological Sciences, Purdue University, West Lafayette, Indiana 47907 USA
}

Mutations in the dachsous gene of Drosophila lead to striking defects in the morphogenesis of the thorax, legs, and wings. The dachsous gene has been cloned and shown to encode a huge transmembrane protein that is a member of the cadherin superfamily, similar to the fat gene reported previously. Both the Dachsous and Fat proteins contain large tandem arrays of cadherin domains-27 and 34, respectively-as compared with 4 cadherin domains in classic vertebrate cadherins. In addition, Dachsous and Fat each has a cytoplasmic domain with sequence similarity to the cytoplasmic $\beta$-catenin-binding domain of classic vertebrate cadherins. The dachsous gene is expressed in the ectoderm of embryos, whereas its expression in larvae is restricted to imaginal discs and specific regions of the brain. The phenotypes of, and genetic interactions between dachsous and fat are consistent with a model in which cell proliferation and morphogenesis of imaginal structures depends on the coupled equilibria between homo- and heterophilic interactions of the Dachsous and Fat cadherin proteins.

[Key Words: Cadherin; cell adhesion; dachsous; disc morphogenesis]

Received March 6, 1995; revised version accepted May 3, 1995.

Our interest in undertaking a molecular genetic analysis of cadherin function in Drosophila was prompted by its apparent importance during vertebrate morphogenesis. Cadherins are glycoproteins that mediate $\mathrm{Ca}^{2+}$-dependent cell adhesion at adherens junctions and desmosomes (for review, see Magee and Buxton 1991; Takeichi 1991; Kemler 1993). All members of the large cadherin gene family share the characteristic cadherin domains thought to be responsible for the $\mathrm{Ca}^{2+}$-dependent cell adhesion. These cadherin domains are $\sim 100$ amino acids long and $30 \%$ homologous to each other. Classic vertebrate cadherins consist of four tandemly repeated extracellular cadherin domains, a single transmembrane domain, and a conserved cytoplasmic domain that interacts via specific catenins with the actin filaments of the cytoskeleton. In humans, cadherins have been implicated in the suppression of metastasis (e.g., Frixen et al. 1991; Vleminckx et al. 1991) and in the autoimmune skin disease pemphigus vulgaris (Amagai et al. 1991).

Two loci in Drosophila were found to encode cadherin domains, the fat $(f t)$ gene at chromosomal position 24D and an unidentified gene at 21D (Mahoney et al. 1991).

Present addresses: ${ }^{4}$ Institute for Plant Biology, University of Zurich, $\mathrm{CH}-$ 8008 Zurich, Switzerland.

${ }^{5}$ The first two authors contributed equally.

${ }^{6}$ Corresponding author.
The $f t$ tumor suppressor gene encodes a novel member of the cadherin superfamily. In contrast to typical vertebrate cadherins that contain four tandem cadherin domains, the extracellular region of the Ft protein consists of 34 tandem cadherin domains, followed by five epidermal growth factor (EGF)-like repeats and two laminin A G-domain-like repeats (Mahoney et al. 1991; Patthy 1992). Recessive lethal mutations in $f t$ cause hyperplastic, tumor-like overgrowth of larval imaginal discs in a cell-autonomous fashion, defects in differentiation and morphogenesis, and death during the pupal stage (Bryant et al. 1988; Mahoney et al. 1991). Recently, a third cadherin, more closely related to classic vertebrate cadherins, was isolated in Drosophila (Oda et al. 1994). The unidentified cadherin gene at 21D will be described here and shown to be encoded by the dachsous (ds) gene, which had been cloned by chromosomal walking in an independent approach to isolate this morphogenetic gene.

The $f t$ and $d s$ genes have long been known to play important roles during imaginal disc development and morphogenesis. A spontaneous mutation at the $d s$ locus, $d s^{1}$, was discovered in 1917 by Calvin Bridges (Stern and Bridges 1926). The first recessive and dominant mutant alleles of $f t, f t^{1}$ and Gull, were isolated 2 years later, and the similarity between their phenotypes and that of $d s^{1}$ suggested that $d s$ and $f t$ might function in the same ge- 
netic pathway (Mohr 1923). Consistent with this suggestion, $d s^{1}$ was shown to suppress the Gull phenotype in that one copy of $d s^{1}$ causes a weak and two copies a strong suppression of Gull (Mohr 1929).

Previous genetic studies suggested that three other genes-comb-gap $(\mathrm{cg})$, four-jointed $(f i)$, and dachs $(d)-$ interact with $d s$. A stronger $d s$ allele, $d s^{38 k}$, exhibits greatly amplified morphogenetic phenotypes in double or triple homozygous mutant combinations with these three genes which, by themselves, are associated with morphogenetic phenotypes in legs and wings (Waddington 1943). It is thus plausible that the unknown products of these three genes participate in the same developmental pathway as the cadherin encoded by $d s$.

As a first step in the unraveling of these complex genetic relationships at the molecular level, we have cloned and identified the $d s$ gene. It was found to encode a huge membrane protein of 3503 amino acids, whose extracellular part consists of 27 tandemly repeated cadherin domains, similar to the previously characterized Drosophila cadherin Ft. In contrast to Ft (Mahoney et al. 1991), Ds contains no extracellular EGF-like or laminin A G-domain-like repeats, which may account for the observation that mutations in $d s$ lead exclusively to defects in morphogenesis and do not affect the control of cell proliferation as do strong $f t$ alleles (Bryant et al. 1988). Similar to $\mathrm{Ft}$, the cytoplasmic portion of the Ds protein shares with classic vertebrate cadherins the domain that interacts with $\beta$-catenin and thus links it to the cytoskeleton (Kemler 1993). The interaction between $f t$ and $d s$ (Mohr 1929) can be explained by a model in which the control of cell proliferation and morphogenesis by their protein products depends on the coupled equilibria between homo- and heterophilic associations of their cadherin domains. Consistent with the morphogenetic role of $d s$, its transcripts are expressed in the embryo, in the larval brain, and in all imaginal discs, where they are frequently found along invaginations or folds separating cells of different fates.

\section{Results}

Cloning of a cadherin-like gene in the chromosomal band $21 D 1,2$

Two different DNA segments encoding cadherin domains were amplified by PCR from genomic Drosophila DNA. One DNA sequence, located in the chromosomal interval 24D, was shown to originate from the $f t$ gene, and the other from an unknown gene at 21D (Mahoney et al. 1991). Independently, a chromosomal walk including the aristaless (al) gene (Schneitz et al. 1993) was extended proximally into the $21 \mathrm{D} 1,2$ region to clone the $d s$ gene. Hybridization of cDNA clones, isolated by the use of the PCR product from 21D as probe, to DNA of the chromosomal walk showed that it mapped to the region of the $d s$ locus. As described below, the cadherin domain was subsequently shown to be encoded by the $d s$ gene.

Starting with the initial PCR product, many overlapping cDNAs were isolated from oligo $(\mathrm{d} T)$-primed as well as randomly primed 9- to 12-hr embryonic cDNA libraries until the 10.7-kb open reading frame (ORF) was covered by a composite cDNA length of $12.4 \mathrm{~kb}$ (Fig. 1). Overlapping cDNAs and the corresponding 12 exons of genomic DNA were sequenced to derive a protein of 3503 amino acids. The entire ORF contains two methionines that are located 40 and 53 amino acids upstream of the initiator methionine of the protein shown in Figure 2. However, because an unusually long signal peptide would result if the first or second methionine were used as initiator, we assume that the protein begins with the third methionine and a signal sequence that is probably cleaved after 20 amino acids. After amino acid 3043 , another stretch of 25 hydrophobic amino acids, presumably a transmembrane domain, is followed by several basic amino acids on the cytoplasmic side, suggesting that $d s$ encodes a transmembrane protein. The amino-terminal extracellular domain includes 27 tandemly repeated domains of $\sim 110$ amino acids each that are similar in sequence to those found in all other members of the cadherin superfamily. In particular, most of the key amino acids of the consensus sequence of cadherin domains and their putative $\mathrm{Ca}^{2+}$-binding sites (Ringwald et al. 1987; Ozawa et al. 1990a) are conserved in the Ds protein (Fig. 2).

Only a short stretch of amino acids separates the last cadherin domain from the transmembrane domain (Fig. 2). This is in contrast to the $\mathrm{Ft}$ protein (Fig. 3A), in which, after the last of its 34 cadherin domains, the extracellular portion includes five EGF-like repeats (Mahoney et al. 1991), the last being flanked by two G-domain-like repeats of laminin A (Patthy 1992; Wodarz et al. 1993).

The cytoplasmic domain of the Ds protein has sequence similarity to that of the classic vertebrate cadherins, such as E-cadherin (Fig. 3B). This sequence, which corresponds to the $\beta$-catenin-binding region in classic cadherins (Nagafuchi and Takeichi 1989; Ozawa et al. 1990b|, is interrupted in the cytoplasmic domain of both $\mathrm{Ds}$ and $\mathrm{Ft}$ (Fig. 3). The intervening peptide between the two conserved regions largely accounts for the larger cytoplasmic domain of Ds as compared with that of vertebrate cadherins.

\section{The cadherin-like protein is encoded by the ds gene}

The $d s$ gene was cloned by extending a $240-\mathrm{kb}$ chromosomal walk, comprising the deficiency $D f(2 L) a l$ at $21 \mathrm{C}$ (Schneitz et al. 1993), by $185 \mathrm{~kb}$ into the chromosomal band $21 \mathrm{D} 1,2$. Mapping the $d s$ cDNAs to the overlapping clones of chromosomal DNA shows that the primary $d s$ transcript extends from a centromere proximal start site over $>65 \mathrm{~kb}$ toward the left telomere of the second chromosome (Fig. 1). Eleven introns were identified by mapping and sequencing all intron-exon boundaries of the genomic DNA. The largest intron is located $\sim 1.7 \mathrm{~kb}$ downstream from the translational start codon and consists of $\sim 40 \mathrm{~kb}$ (Fig. 1).

Several breakpoints of chromosomal rearrangements and restriction fragment length polymorphisms (RFLPs) 


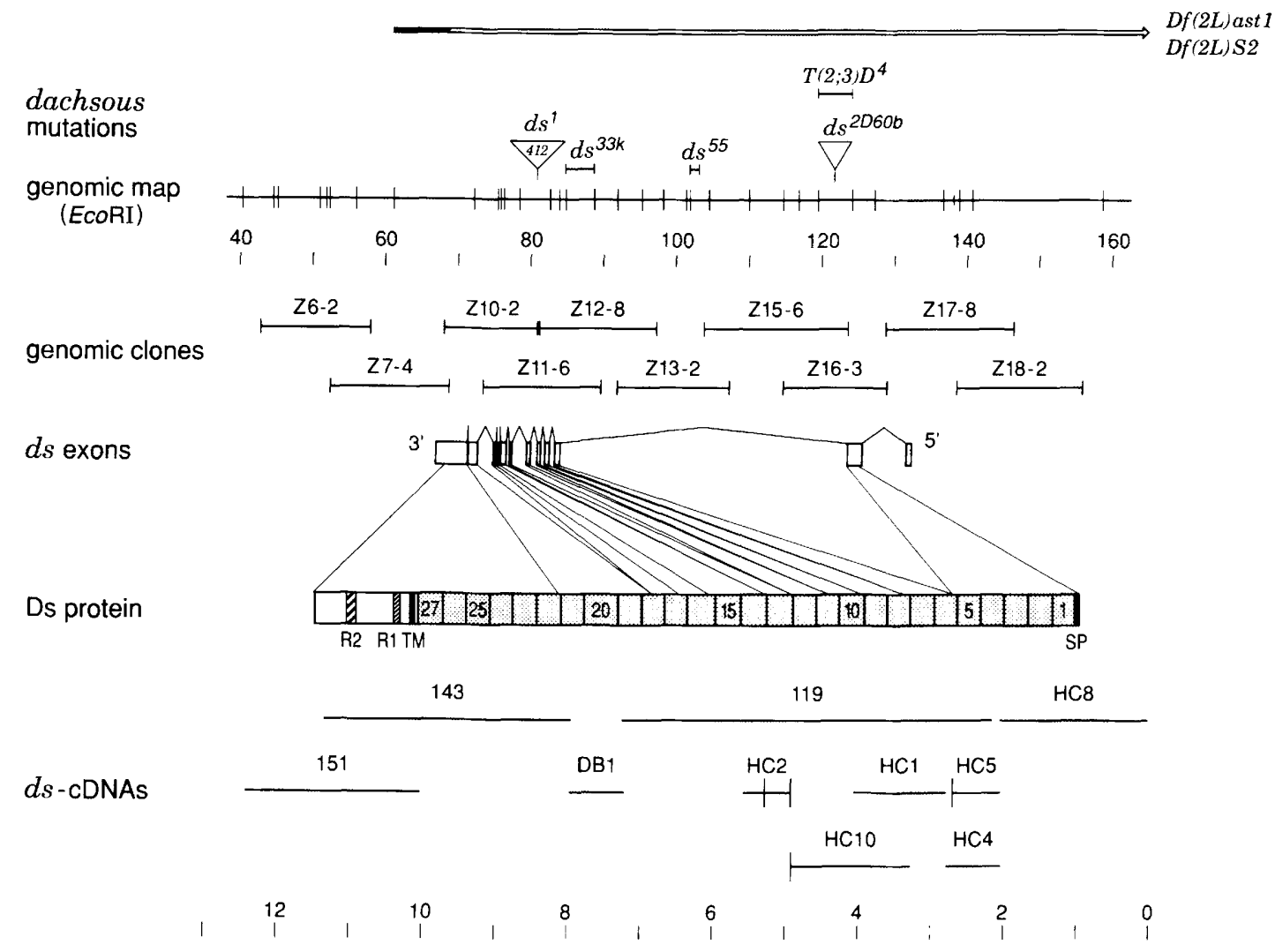

Figure 1. The $d s$ gene encodes a huge transmembrane protein. (Top) Several rearrangements of the $d s$ locus (cf. Table 1) are mapped with respect to a genomic EcoRI map (a shorter vertical line separates two neighboring EcoRI fragments whose order has not been determined) at chromosomal band $21 \mathrm{Dl}, 2$ (brackets and open bar indicate the limits of the regions that include the breakpoints). The scale underneath indicates the distance (in $\mathrm{kb}$ ) from the origin of a chromosomal walk (located at 21C7,8; Schneitz et al. 1993) that includes the clones Z6-2 to Z18-2 isolated from a $K s^{S B 1} / C y O$ library in EMBL4. Below the genomic clones, the exon/intron structure of the $d s$ transcript is shown with the corresponding coding regions of the Ds protein consisting of a signal peptide (SP), 27 extracellular cadherin domains (stippled), a transmembrane domain (TM), and a cytoplasmic domain including two regions (R1, R2) that are homologous to the $\beta$-catenin-binding domain of vertebrate cadherins (cf. Fig. 3). (Bottom) The location of several sequenced $d s \mathrm{cDNAs}$ are shown with respect to the encoded Ds protein with vertical lines indicating the positions of unspliced intron sequences /scale underneath in $\mathrm{kb}$ ).

of $d s$ mutant alleles (Table 1) have been mapped throughout the gene encoding the large cadherin-like protein (Fig. 1). Two deficiencies uncovering $d s, D f(2 L)$ ast1 and $D f(2 L) S 2$, delete at least $65 \mathrm{~kb}$ of the $d s$ transcript and its entire upstream region. In contrast, $D f(2 L)$ ast 10 , which complements other $d s$ mutant alleles, is located proximal to clone Z18-2 of our chromosomal walk (Fig. 1). Moreover, two inversion breakpoints associated with $d s$, $d s^{55}$ on the $S M 5$ balancer chromosome, and $d s^{33 k}$ on the In(2LR)Pm chromosome, are located within the large intron of the $d s$ transcript.

A P-element-lacZ enhancer trap line, 2D60 /kindly provided by D. Cimbora and S. Sakonju, University of Utah, Salt Lake Cityl, that exhibits a strong $d s$ phenotype in trans over other $d s$ alleles, contains two P elements on the second chromosome whose flanking DNA was recovered by plasmid rescue (D. Cimbora and S. Sakonju, unpub.). One of these insertions, 2D60b, maps to the same 4.7-kb genomic EcoRI fragment as the $3^{\prime}$ end of the second exon and is located $1.9 \mathrm{~kb}$ downstream from the $5^{\prime}$ end of the $40-\mathrm{kb}$ intron (Fig. 1). The other P ele- ment was removed by recombination to produce a line retaining a single $\mathrm{P}$ element at $21 \mathrm{D} 1,2$. The chromosome containing this single $\mathrm{P}$ element in the $40-\mathrm{kb}$ intron fails to complement $d s$ and thus is itself a $d s$ allele, $d s^{2 D 60 b}$. This conclusion is corroborated by the observation that excision of the $\mathrm{P}$ element in 15 independent lines was accompanied by the loss of the $d s$ phenotype.

The location of these insertion and inversion breakpoints within the large intron, however, does not exclude the possibility that $d s$ is located entirely within the $40-\mathrm{kb}$ intron and is different from the cadherin-like gene. Therefore, additional $d s$ alleles were screened for breakpoints or RFLPs by genomic Southern blot analysis, using cloned cDNAs as probe. In these screens two alleles were found to affect the coding region of the $d s$ transcript (RFLPs of $d s$ alleles that lie entirely within introns would have escaped detection). First, a reciprocal translocation between the second and third chromosome that breaks at $21 \mathrm{D}$ of the second chromosome, $d s^{D 4}$ (Craymer 1980 l, translocates the $5^{\prime}$ portion, including part of the $40-\mathrm{kb}$ intron of $d s$, to the third chromosome, and thus 


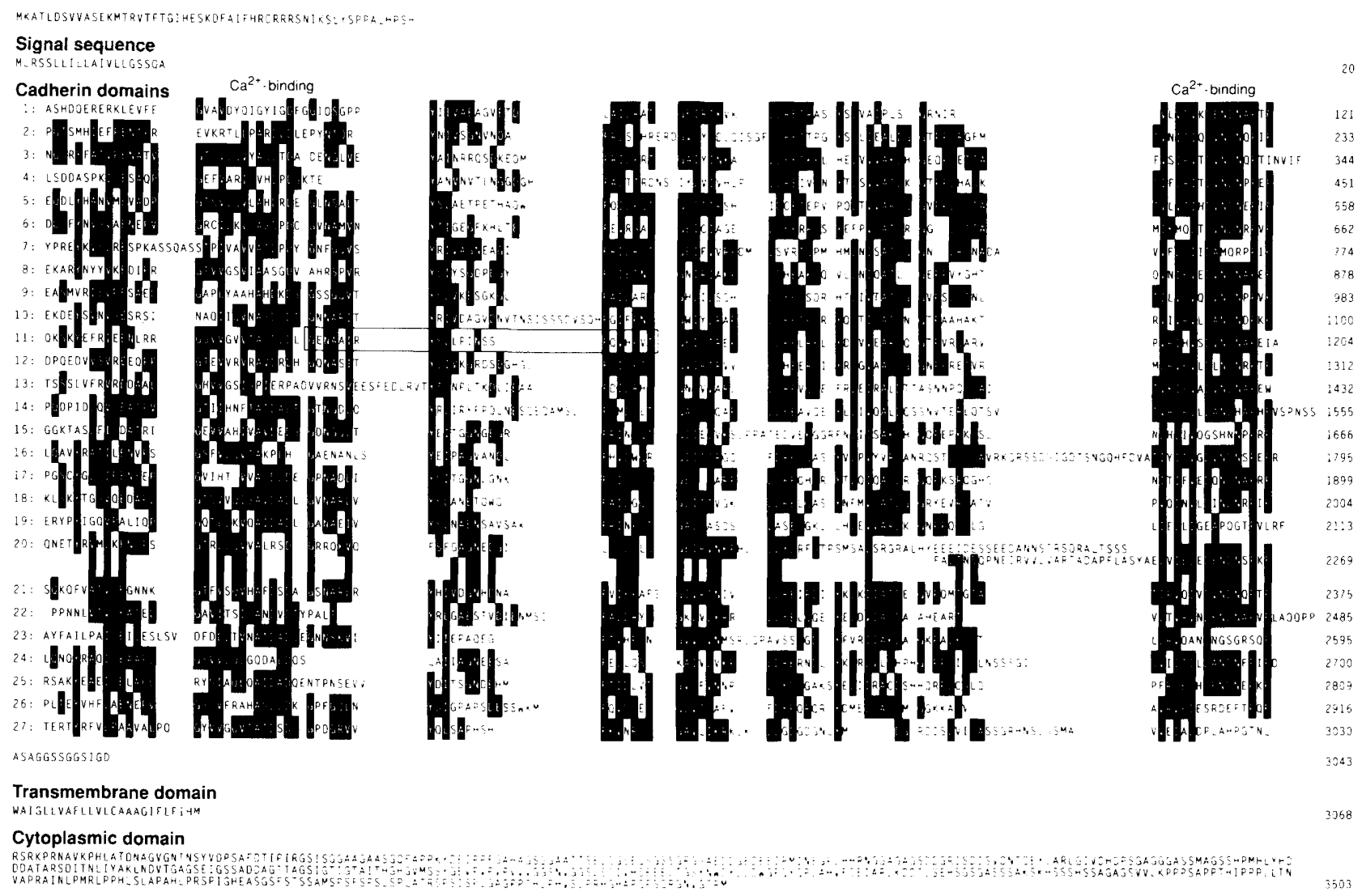

Figure 2. The Ds protein belongs to the cadherin superfamily. The amino acid sequence of the putative Ds protein is shown to consist of a signal sequence, 27 cadherin domains, a transmembrane domain, and a cytoplasmic domain. The cadherin domains with their two characteristic $\mathrm{Ca}^{2+}$-binding regions (Ringwald et al. 1987; Ozawa et al. 1990a) are aligned for optimal homology between themselves, which results in excellent alignment with the cadherin domains of $\mathrm{Ft}$ (Mahoney et al. 1991) and classic vertebrate cadherins (Hatta et al. 1988). To illustrate the extent of homology among the Ds cadherin domains, one or few amino acids that occur at a certain position with high frequency are highlighted as dark boxes, emphasizing the high conservation of a motif rather than of a unique amino acid sequence among cadherin domains. Note that if few amino acids are preferred at the same position, they belong frequently, yet not always, to a group of amino acids with similar properties $(S / T ; I / L / V ; E / D ; K / R)$. The amino acid sequence has been derived from the longest ORF of overlapping cDNAs and their corresponding genomic DNAs. Translation of the Ds protein is assumed to start at the third methionine of the ORF, which immediately precedes the putative signal siquence and, hence, is designated as position 1 of the amino acids numbered at right. The 23 amino acids that are deleted from the eleventh cadherin domain in the Ds ${ }^{1}$ mutant protein are boxed.

separates the region encoding the first five cadherin domains from the remaining 3 ' portion of $d s$.

In addition, RFLPs of the $d s^{1}$ allele were detected. Isolation of $d s^{1}$ DNA from a genomic library and sequencing revealed a $7.6 \mathrm{~kb}$ insertion of the 412 transposable element (Finnegan et al. 1978; Will et al. 1981; Shepherd and Finnegan 1984) within the region encoding the eleventh cadherin domain very close to the $3^{\prime}$ end of the fifth exon (Fig. 4). Because $d s^{1}$ is a weak allele, the question arises why the insertion of a large transposon in the middle of the ORF does not cause a more severe effect on the phenotype. The answer comes from sequence analysis of $d s^{1}$-cDNA, which reveals in embryos and third-instar larvae three types of splice products that lack the 412 insertion. Apparently, the wild-type splice donor site of the fifth intron is inactivated by the close proximity of the 412 insertion. As a result, three cryptic splice donor sites are uncovered, two upstream of and close to the 412 insertion and a third site $30 \mathrm{bp}$ within the 412 element
(Fig. 4). Whereas one of the two upstream $d s^{1}$ splice products generates a frameshift resulting in a truncated, secreted protein, the reading frame of the other product remains unchanged and encodes a protein in which merely 23 amino acids of the eleventh cadherin domain are deleted (Figs. 2 and 4). The use of the third cryptic splice donor site also results in the premature release and secretion of a truncated protein (Fig. 4). Because $d s^{1}$ is a spontaneous mutation (Stern and Bridges 1926), it is not surprising that it is caused by the insertion of a transposon. Interestingly, the spontaneous $f t$ allele Gull is also an insertion of the 412 transposon in the ORF of a cadherin domain (Mahoney et al. 1991).

\section{Expression of ds in embryonic ectoderm, larval brain, and imaginal discs}

Consistent with a composite cDNA length of $12.4 \mathrm{~kb}$, Northern blot analysis revealed a very large transcript 


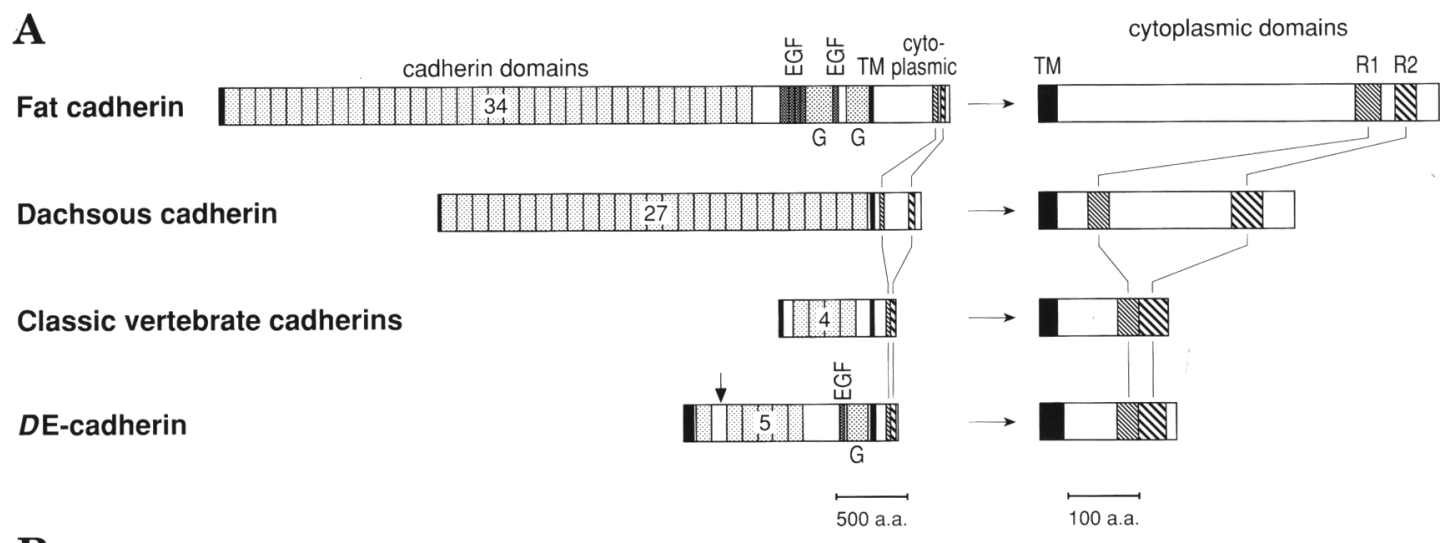

B

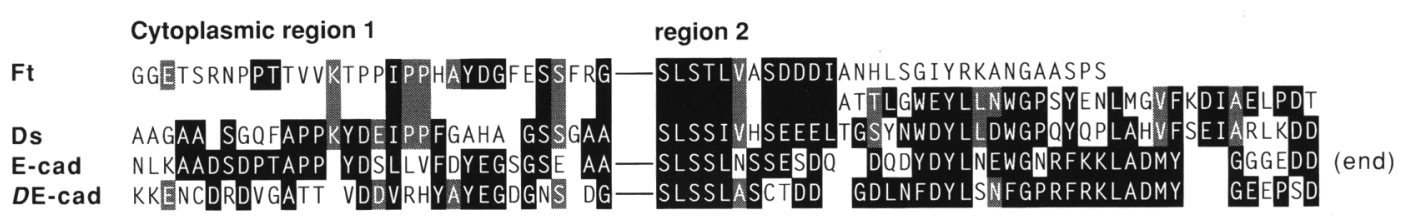

Figure 3. Structural similarities of Ds with $\mathrm{Ft}, D E$-cadherin, and classic vertebrate cadherins. $(A)$ Key features of the predicted protein products from the $d s$ and $f t$ genes (Mahoney et al. 1991), as well as of the classic vertebrate cadherins (Hatta et al. 1988) and the recently isolated DE-cadherin of Drosophila (Oda et al. 1994), include the signal sequence (black), extracellular cadherin domains (lightly stippled), a transmembrane domain (TM), and a cytoplasmic domain. Note that Ds and Ft differ from classic vertebrate cadherins mainly in their much larger number of tandemly repeated cadherin domains and in a larger cytoplasmic domain whose homology to the vertebrate $\beta$-catenin-binding domain is split into two regions, $\mathrm{Rl}$ and $\mathrm{R} 2$, illustrated in detail in $B$. In addition, the extracellular portion of $\mathrm{Ft}$ includes five EGF-like repeats (Mahoney et al. 1991) and two G-domain-like repeats of laminin A (Patthy 1992; Wodarz et al. 1993) that are both absent in Ds and classic cadherins but present in DE-cadherin (Oda et al. 1994). The vertical arrow in $D E$-cadherin indicates that its amino-terminal portion, including a sixth cadherin domain, is probably cleaved off upon maturation (Oda et al. 1994). (B) Homology in two conserved regions, R1 and R2, of the cytoplasmic domains of Ft and Ds with the $\beta$-cateninbinding portion of the cytoplasmic domain of E-cadherin (Nagafuchi et al. 1987; Ringwald et al. 1987), a classic vertebrate cadherin (Hatta et al. 1988), and DE-cadherin (Oda et al. 1994). Cytoplasmic regions 1 and 2 of Ds are interrupted by a stretch of 172 amino acids as indicated by a gap. Conservation between Drosophila $(\mathrm{Ft}$, Ds, DE-cad) and vertebrate (E-cad) sequences is indicated by black boxes; amino acids whose conservation is restricted to the Drosophila cadherins are shown by shaded boxes.

well above $9.5 \mathrm{~kb}$ that persisted throughout embryogenesis and was also present in third-instar larvae and adults (not shown). In addition, a less abundant transcript of $\sim 8$ $\mathrm{kb}$ was detected at all developmental stages. It is not clear whether this transcript, which is smaller than the 10.7-kb ORF, encodes a shorter form of the Ds protein.

The spatial distributions of $d s$ transcripts were analyzed by in situ hybridization to whole-mount embryos (Fig. 5). The first $d s$ transcripts are detectable during gastrulation in a pair-rule pattern of six weak epidermal stripes and in a prominent stripe at the amnioproctodeal invagination (Fig. 5A). During germ-band extension, $d s$ RNA accumulates in a segmentally repeated pattern of 14 stripes and in the procephalon (Fig. 5B). The most pronounced expression of $d s$ is observed during the extended germ-band stage mainly in the forming tracheal pits (Fig. 5C). At the beginning of head involution, $d s$ RNA appears in the anterior spiracles and again in stripes of the segmental grooves and buds while it remains weakly expressed in the remnants of the tracheal pits (Fig. 5D). In addition, $d s$ RNA is first detected in the primordial leg discs that form in the ventral posterior part of each thoracic segment (Bate and Martinez-Arias
1991; Cohen et al. 1991). At late stage 14, $d s$ is expressed strongly in the nearly fused labial buds and at invaginations of the maxillary segment while it continues to be expressed in the leg disc primordia (Fig. $5 \mathrm{E}, \mathrm{H}$ ), along the segmental folds (Fig. 5E,G), and probably in the apodemes (Fig. 5G). After dorsal closure, $d s$ expression persists only in the apodemes and in the head region (Fig. $5 \mathrm{~F}, \mathrm{I})$.

In third-instar larvae, $d s$ transcripts are found in the imaginal discs and the brain (Fig. 6). In the supraesophageal ganglion, $d s$ is expressed in two areas of the optic lobe and in a region that might belong to the mushroom body (Fig. 6A). In imaginal discs, strong $d s$ expression occurs frequently along folds separating the anlagen of distinct imaginal structures (Fig. 6B-F). In the antennal disc, $d s$ is expressed in the arista and first and second antennal segment anlagen while, in the eye disc, $d s$ transcripts are abundant along the folds of the future bristle region of the head capsule (Fig. 6B). Expression of $d s$ is observed further in humeral (Fig. 6C) as well as in genital and labial discs (not shown). In leg discs, $d s$ is expressed strongly in the anlagen of the tarsal joints and, particularly, of the most proximal leg segment (Fig. 6D). Similarly, $d s$ expression is strongest in the pleural, dorsal 
Table 1. ds alleles

\begin{tabular}{lllr}
\hline Allele & Origin & Discoverer & Eclosion \\
\hline$d s^{1}$ & spont. & Bridges, 17k12 & $100 \%$ \\
$d s^{W}$ & spont. & Bridges, 29d24 & $40 \%$ \\
$d s^{33 k \text { a }}$ & spont. & Bridges, 33k28 & N.A. \\
$d s^{38 k}$ & spont. & Waddington, 38k & $40 \%$ \\
$d s^{48 k}$ & unknown & García-Bellido & N.D. \\
$d s^{55 \mathrm{~b}}$ & X-ray & Craymer & N.A. \\
$d s^{F 31 B}$ & EMS & Postner & N.D. \\
$d s^{M 56}$ & EMS & Postner & N.D. \\
$d s^{M 114}$ & EMS & Postner & N.D. \\
$d s^{M 116}$ & EMS & Postner & N.D. \\
$d s^{M 121}$ & EMS & Postner & N.D. \\
$d s^{M 208}$ & EMS & Postner & N.D. \\
$d s^{M 213}$ & EMS & Postner & $40 \%$ \\
$d s^{2 D 60 b}$ & P-element & Cimbora & N.D. \\
$D f(2 L) S 2$ & X-ray & Lewis & N.A. \\
$d f(2 L) a s t 1$ & X-ray & Lewis & N.A. \\
$d s^{D 4 c}$ & X-ray & Sigmund (1978) & N.A. \\
\hline A large & ntm & &
\end{tabular}

A large number of alleles define the $d s$ locus. The allele designation, origin ('spont.) spontaneous; (EMS) ethylmethane sulfonate], and discoverer of the mutant, and the rate of eclosion [(N.D.) not determined; (NA) not applicable because the chromosome has many additional inversions and mutations| are shown for the $d s$ alleles discussed in this paper. The mutant stocks were obtained from Antonio García-Bellido, Marya Postner (in Eric Wieschaus' laboratory), Dan Cimbora (in Shige Sakonju's laboratoryl, and Michael Ashburner $\left(d s^{D 4}\right)$ as indicated. The remaining stocks were from the Bloomington Stock Center. Although originally described as a dominant mutation (see Lindsley and Zimm 1992), the $d s^{w}$ allele showed no dominant effects in our hands.

${ }^{a} \mathrm{On} \operatorname{In}(2 L R) b w^{V 1}$ also known as $P m$ balancer; cytology, In(2LR) 21C8-D1;60D1-2.

${ }^{\mathrm{b}}$ On In(2LR)SM5, also known as SM5 balancer; cytology, In(2L) 2ID2-3;36C

${ }^{\mathrm{c}}$ On $T(2 ; 3) D^{4}$; cytology, $T(2 ; 3) 21 D ; 70-71$.

hinge, and prescutal regions of the wing disc, whereas the anlage of the future wing blade is virtually free of $d s$ RNA (Fig. 6E). In contrast, the haltere disc exhibits high levels of $d s$ transcripts in the capitellum, pedicel, and scabellum while expression in the notum remains relatively low (Fig. 6F).

We also examined the patterns of lacZ expression in the $d s^{2 D 60 b}$ enhancer trap P-element insertion stock (Fig. 7). The patterns reveal that the enhancer detected by the P-element insertion in the large first intron (Fig. 1) controls expression both in embryos and larvae. However, while the patterns of $l a c Z$ and $d s$ expression are virtually indistinguishable in third-instar larvae, they differ significantly during embryogenesis (cf. Figs. 5 and 7). For example, $l a c Z$ is expressed in a weak anterior stripe during cellularization (Fig. 7A) and, during gastrulation, in the ventral furrow, along the cephalic furrow, and in the procephalon (Fig. 7B) but fails to show the early pair-rule pattern of $d s$ stripes (Fig. 5A). During germ-band elongation and the extended germ-band stage, lac $Z$ fails to be expressed in stripes or in the tracheal pits (Fig. $7 C, D$ ). Only after dorsal closure, $l a c Z$ and $d s$ expression are nearly congruent except that $l a c Z$ is expressed ectopi- cally in the eighth abdominal segment, but fails to be expressed in the frontal sac (cf. Figs. 5F,I and 7F,G). The differences in embryonic expression patterns between $d s$ and lac $Z$ might result from an incompatibility of some of the embryonic $d s$ enhancer elements with the basal promoter combined with lacZ ( $\mathrm{Li}$ and Noll 1994).

\section{Mutations in the ds gene lead to defects in morphogenesis}

The adult phenotype of $d s$ mutants is consistent with the high levels of $d s$ transcript in imaginal discs. In all known alleles (Table 1), defects are seen with $100 \%$ penetrance in the legs, wings, and thorax. In contrast, eye defects, apparent as rough patches, occur at a low frequency. On $d s$ wings, the anterior cross-vein is displaced distally, that is, closer to the posterior cross-vein (Fig. $8 \mathrm{~A}, \mathrm{C}, \mathrm{E}, \mathrm{G})$, the legs are stubby with a reduced number of tarsal joints in stronger alleles (Fig. 8B,D,F,H), and the thorax is broadened (Waddington 1943). These adult phe-

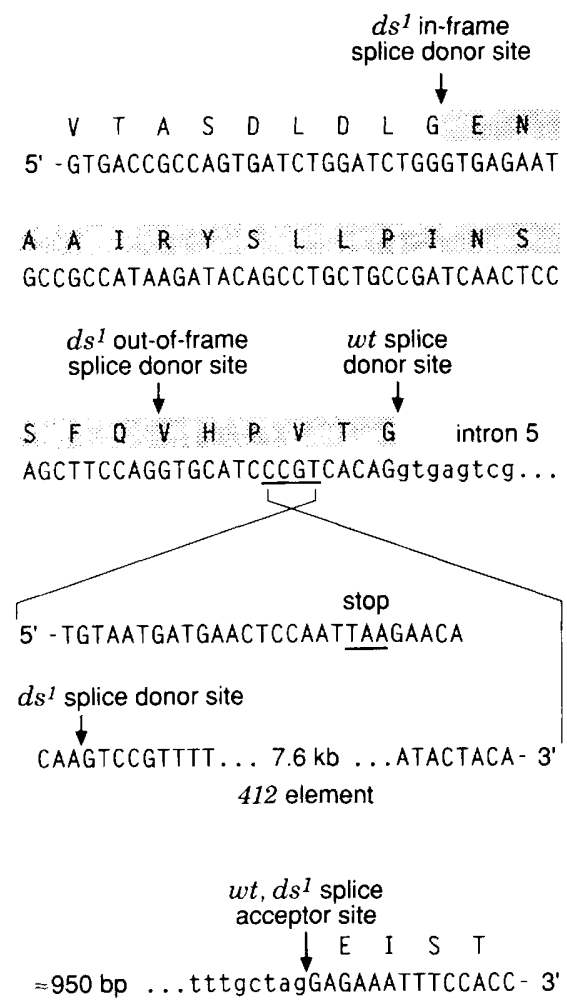

Figure 4. The $d s^{1}$ allele generates an altered form of the Ds protein. The $d s^{1}$ allele is an insertion of the 412 transposon generating a deletion of 23 amino acids from the eleventh cad herin domain due to an altered splicing pattern. The genomic DNA sequence surrounding the insertion in $d s^{1}$ of the 412 transposon at the $3^{\prime}$ end of exon 5 is shown. Above the DNA sequence the corresponding amino acid sequence of the eleventh cadherin domain is derived. Only one of the three cryptic splice donor sites of intron 5 that are observed in $d s^{1}$ is in-frame with the wild-type splice donor site and hence results in the deletion of the 23 shaded amino acids. The two other splice donor sites of $d s^{1}$ generate truncated proteins because of premature termination. 
Figure 5. The $d s$ transcript is expressed in ectodermally derived tissues of wild-type embryos. Whole-mount embryos, hybridized with a digoxigenin (DIG)-labeled $d s$ cDNA probe (combined inserts of $\mathrm{HC} 8,119$, and 143 cDNA clones in Fig. $1)$, are shown at stage $6(A)$, early stage $10(B)$, stage $11\{C)$, early $(D)$ and late stage $14(E)$, or stage $16(F)$ as lateral $|A-D\rangle$, ventral $(E)$, or dorsal view (F). Enlarged optical sections illustrate parts of embryos in $G-H$. $(G)$ Dorsal view of the posterior thoracic and anterior abdominal segments (T2A2) of a stage 15 embryo, demonstrating $d s$ expression along both sides of the intersegmental grooves; $(H)$ lateral view of thorax of stage $14 \mathrm{em}$ bryo, showing $d s$ expression in leg disc primordia; (I) dorsal view of head of stage 16 embryo, illustrating $d s$ expression in derivatives of the clypeolabral (lb, dpo, and epiphysis), labial (labial sensory organ and probably lower lip organ, li), and intercalary segment (ho), and in the anterior part of the frontal sac $(\mathrm{fs})$. Embryos are staged according to Campos-Ortega and Hartenstein (1985) and oriented with anterior to the left; lateral views are shown with dorsal side up. Arrows point at tracheal pit $|C|$, anterior spiracle $(D)$, and intersegmental groove and apodeme $(G)$; arrowheads indicate leg disc primordia $(D, E, H, I)$. (Al) First abdominal segment; $(\mathrm{an} / \mathrm{mx})$ antennal-maxillary sensory organ; (api) amnioproctodeal invagination; (as) amnioserosa; (cf) cephalic furrow; (cl) clypeolabrum; (dpo) dorsal pharyngeal organ; (fs) frontal sac; (ho) hypopharyngeal organ; (lb) labrum; (li) labial segment; (md) mandibular segment; $|\mathrm{mx}\rangle$ maxillary segment; $(\mathrm{pc})$ pole cells; (st) stomodeum; (TI) prothoracic segment.
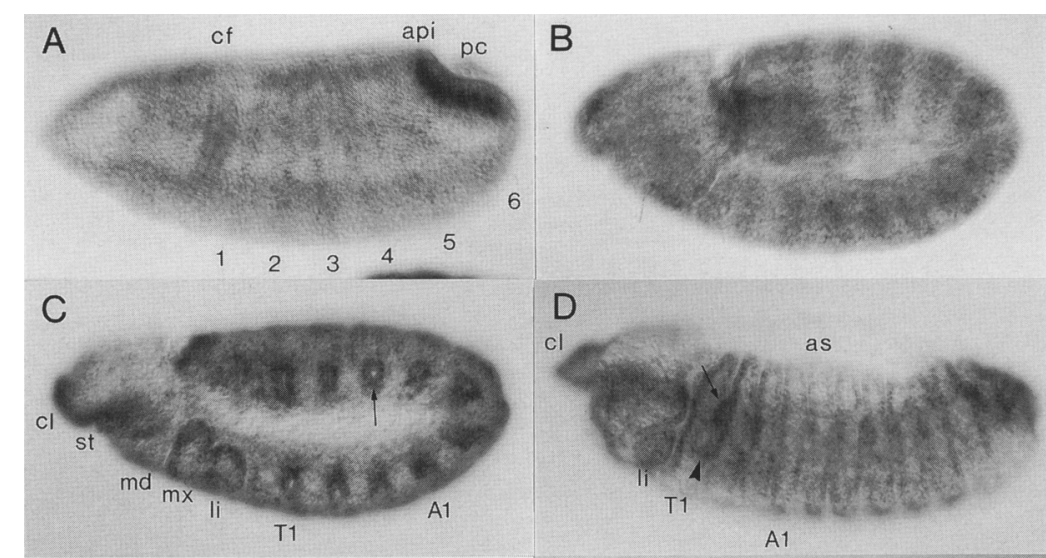

E

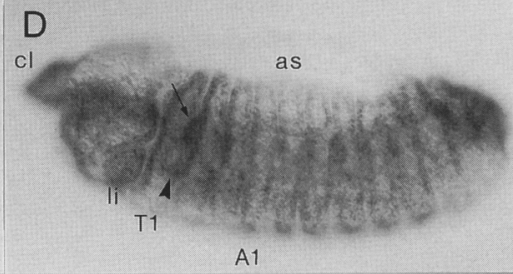

F
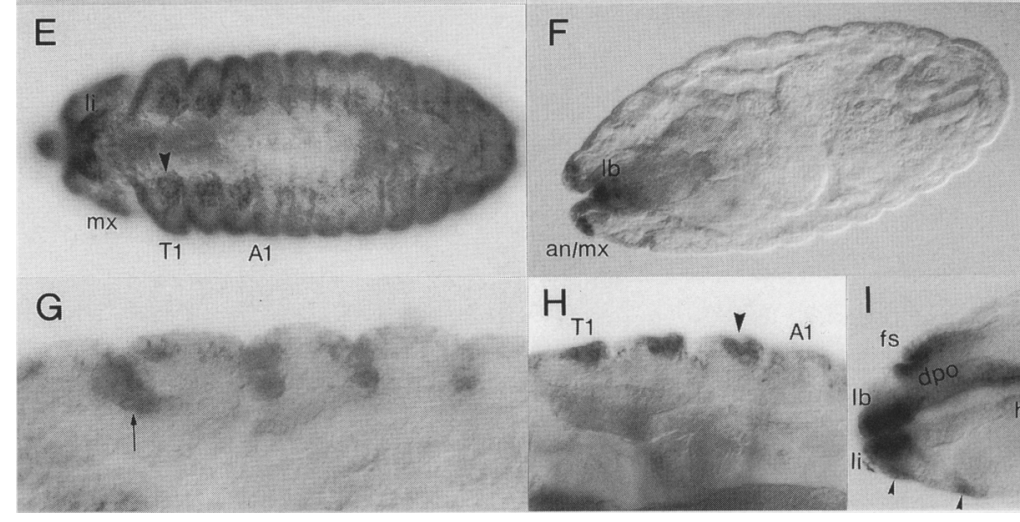

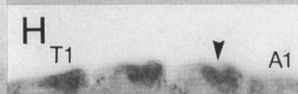

I

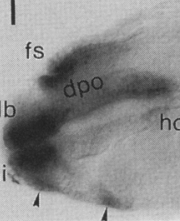

notypes are more pronounced in stronger mutant alleles, with the addition of duplicated bristles on the notum and wings stiffly held out with broken and ectopic crossveins. Several of the $d s$ alleles listed in Table 1 have been examined in homozygous and transheterozygous combinations for the severity of their mutant phenotypes. Clearly, $d s^{1}$ is the weakest known $d s$ allele, as it is the only fully viable allele when combined with itself or any of the other alleles, including the two deficiencies $D f(2 L) S 2$ and $D f(2 L)$ ast 1 , and displays the weakest phenotype (Fig. 8C-F). All other allelic combinations exhibit various degrees of pupal lethality and eclose with a correspondingly reduced efficiency. In the strongest combinations, only a very low percentage (on the order of $1 \%$ ) of extremely disfigured escapers emerges from the pupal cases. These adults have difficulty walking, cannot jump or fly, do not reproduce, and usually die within a few days after eclosion.

It is uncertain whether any of the known $d s$ alleles are null alleles, although we expect the molecular lesions of $d s^{D 4}, d s^{33 k}$, and $d s^{55}$ to generate a secreted, truncated Ds protein (Fig. 1) that might be without function. Combinations of $d s^{33 k}$ and $d s^{55}$ with each other or with the two deficiencies eclose with the lowest frequency and show very strong deformations of thorax, legs, and wings. Because the P-element insertion $d s^{2 D 60 b}$ behaves very sim- ilarly, it might also be a null allele. We conclude that the strongest $d s$ alleles are probably null alleles but are not completely lethal before eclosion. Additional strong alleles are $d s^{38 k}$ and $d s^{M 213}$ which, when combined with one of the two deficiencies, eclose only rarely $(<5 \%)$. These are probably not null alleles, as they eclose with a much higher efficiency $(\sim 40 \%)$ in homozygous or transheterozygous combinations, although the escapers are highly deformed (Fig. $8 \mathrm{G}, \mathrm{H}$ ) and die within a few days after eclosion. Surprisingly, no embryonic phenotype has been observed even of the strongest allelelic combinations.

The $f t$ gene has been termed a tumor suppressor gene because recessive null alleles give rise to mutants with overgrown imaginal discs (Bryant et al. 1988; Mahoney et al. 1991). Because of the similarity between the overall structures of the Ds and Ft proteins, the expression of their transcripts, their viable adult mutant phenotypes, and the lethal stage of their putative null alleles, we wondered whether strong $d s$ alleles would also give rise to overgrowth phenotypes. To test this possibility, imaginal discs of homozygous or transheterozygous combinations of two strong $d s$ alleles, $d s^{M 213} / d s^{M 213}$ and $d s^{M 213 /}$ $d s^{33 k}$, were compared in size with those from $d s^{M 213 /}$ $C y O$ and wild-type Canton-S larvae and examined for a possible overgrowth phenotype. All of the $d s$ discs ex- 


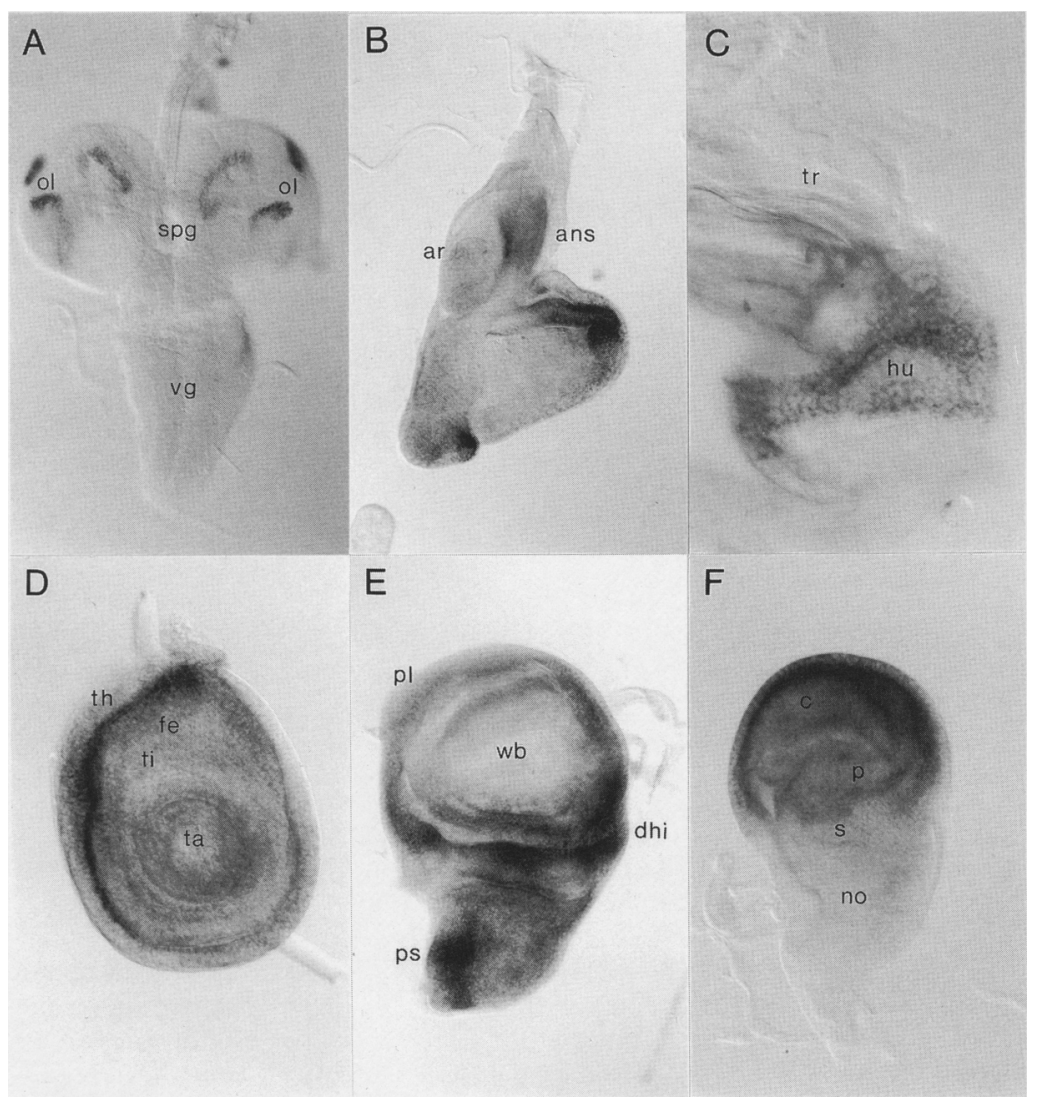

Figure 6. The $d s$ transcript is expressed in specific regions of the larval brain and imaginal discs. Whole-mount late third-instar imaginal discs and larval brain were hybridized with the same DIG-labeled $d s$ cDNA probe as used in Fig. 5. Expression of $d s$ transcripts is shown in the supraesophageal ganglion or brain $(A)$, and in imaginal discs of the eye-antenna $(B)$, humerus $|C|$, metathoracic leg $|D|$, wing $(E)$, and haltere $(F)$. (ans) Antennal segments; (ar) arista; (c) capitellum; (dhi) dorsal hinge; (fe) femur; (hu) humeral disc; (no) notum; (ol) optic lobe; (p) pedicel; (pl) pleura; (ps) prescutum; (s) scabellum; $(\mathrm{spg})$ supraesophageal ganglion; (ta) tarsus; (th) thorax (ti) tibia; (tr) tracheae; (vg) ventral ganglion; $(\mathrm{wb})$ wing blade. amined were within the size range observed in wild-type larvae and exhibited no overgrown imaginal discs. Therefore, in contrast to mutations in the $f t$ gene, $d s$ mutations appear to alter imaginal disc morphogenesis exclusively without affecting cell proliferation.

\section{Discussion}

Two Drosophila genes, $f t$ (Mahoney et al. 1991) and $d s$, as shown here, belong to the cadherin superfamily and encode huge transmembrane proteins that contain large numbers of tandem cadherin domains $(27$ for the Ds and 34 for the Ft protein). Interestingly, both genes have been studied for decades because of the striking similarity in their mutant phenotypes observed in adult structures derived from imaginal discs (Mohr 1923; Stern and Bridges 1926), and because of their genetic interactions with each other (Mohr 1929) and with several other genes involved in the morphogenesis of imaginal discs (Waddington 1943).

Although the Ds and Ft proteins are quite similar, they differ in one important aspect. In contrast to Ds, $\mathrm{Ft}$ includes five EGF-like repeats and two laminin A G-domain-like repeats in the extracellular portion between the cadherin domains and the transmembrane segment (Mahoney et al. 1991; Patthy 1992). This structural difference between the products of the two genes is paralleled by an important difference in the spectrum of their mutant phenotypes. Although viable mutations in both genes lead to similar defects in the morphogenesis of imaginal discs, strong mutations in $f t$, but not in $d s$, lead to tumor-like hyperplastic growth of imaginal discs (Bryant et al. 1988). This overgrowth phenotype of lethal $f t$ alleles is cell autonomous (Mahoney et al. 1991), indicating that the $\mathrm{Ft}$ protein acts as signal receptor in the control of cell proliferation. Thus, it is attractive to speculate that the EGF-like repeats and the laminin A G-domain-like repeats specific for the $\mathrm{Ft}$ protein are responsible for its tumor suppressor function by transmitting a signal regulating cell proliferation (Mahoney et al. 1991). On the other hand, the protein domains common to $\mathrm{Ft}$ and Ds play similar roles in the morphogenesis of imaginal discs.

\section{Do Ds and Ft interact with the cytoskeleton-like classic vertebrate cadherins?}

Classic vertebrate cadherins mediate cell adhesion at adherens junctions. Adherens junctions play a central role in morphogenesis by regulating not only cell adhesion but also cellular polarity, changes in cell shape by interaction with the actin cytoskeleton, and signal transduction. Recently, a cadherin was isolated from Drosophila, $D E$-cadherin, whose structure and properties are very similar to those of classic vertebrate cadherins (Oda et al. 1994). DE-cadherin is part of a membrane-associated complex that includes the cytoplasmic proteins $D \alpha$-catenin and Armadillo (Arm), the Drosophila homologs of 




vertebrate $\alpha$ - and $\beta$-catenin (Oda et al. 1993; Peifer 1993). The highly polarized subcellular distribution of this complex to the lateral-apical interfaces of epithelial cells suggests that it forms intercellular adherens junctions (Peifer et al. 1993a,b; Oda et al. 1994) homologous to those of vertebrates (Takeichi 1991; Kemler 1993).

Ds and Ft differ from classical vertebrate cadherins and $D E$-cadherin mainly in the much larger number of extracellular cadherin domains (Fig. 3A). In addition, DE-cadherin and Ft have EGF- and laminin A G-domain-like repeats in their extracellular domain that are absent in Ds and classic cadherins. All three Drosophila cadherins, $\mathrm{Ft}$, Ds, and DE-cadherin, have a cytoplasmic domain with significant sequence similarity to classic vertebrate cadherins in the region that is known to bind $\beta$-catenin (Nagafuchi and Takeichi 1989; Ozawa et al. 1990b), an actin-associated protein thought to anchor the classic cadherins at adherens junctions to the cytoskeleton (Kemler 1993). However, in contrast to vertebrate cadherins and $D E$-cadherin, this putative $\beta$-catenin-binding domain is split by a short and a long intervening region in Ds and Ft, respectively (Fig. 3). Despite this interruption in the $\beta$-catenin binding site, the cytoplasmic domain might still be able to link Ds and/or Ft to the actin cytoskeleton. It is therefore conceivable that Ds and $\mathrm{Ft}$ regulate morphogenesis and cell proliferation as components of adherens junctions in embryos or imaginal discs via catenins such as Armadillo and Do-catenin. Al- though we could not demonstrate a genetic interaction between $d s$ and arm in double heterozygotes $(\mathrm{H}$. Clark, unpubl.), an interaction between Ds and Arm is not excluded because this test might not be sensitive enough. It is also possible that the cytoplasmic domains of Ds and $\mathrm{Ft}$ interact with yet another $\beta$-catenin-like Drosophila protein.

\section{Do Ds- or Ft-like cadherins also exist in vertebrates?}

It is not known whether vertebrates also have large $\mathrm{Ft}$ - or Ds-like members of the cadherin superfamily and whether they also have cadherins containing EGF-like and laminin A G-domain-like repeats. It will be of interest to determine whether vertebrates do have large cadherins like Ds and $\mathrm{Ft}$ and whether they too play major roles in tissue morphogenesis and growth control. It is possible that $\mathrm{Ft}$ and Ds define a new subfamily of the cadherin superfamily and that such large cadherins in both vertebrates and insects play a major role in tissue morphogenesis. Alternatively, if only insects like fruitflies possess such enormous cadherins that are used primarily for imaginal disc morphogenesis, as is the case for Ds and $\mathrm{Ft}$, it will be interesting to learn what constraints of that particular developmental process in insects might have led to the evolution of such unusually large cadherins or, alternatively, what constraints in vertebrates might have suppressed their evolution. 

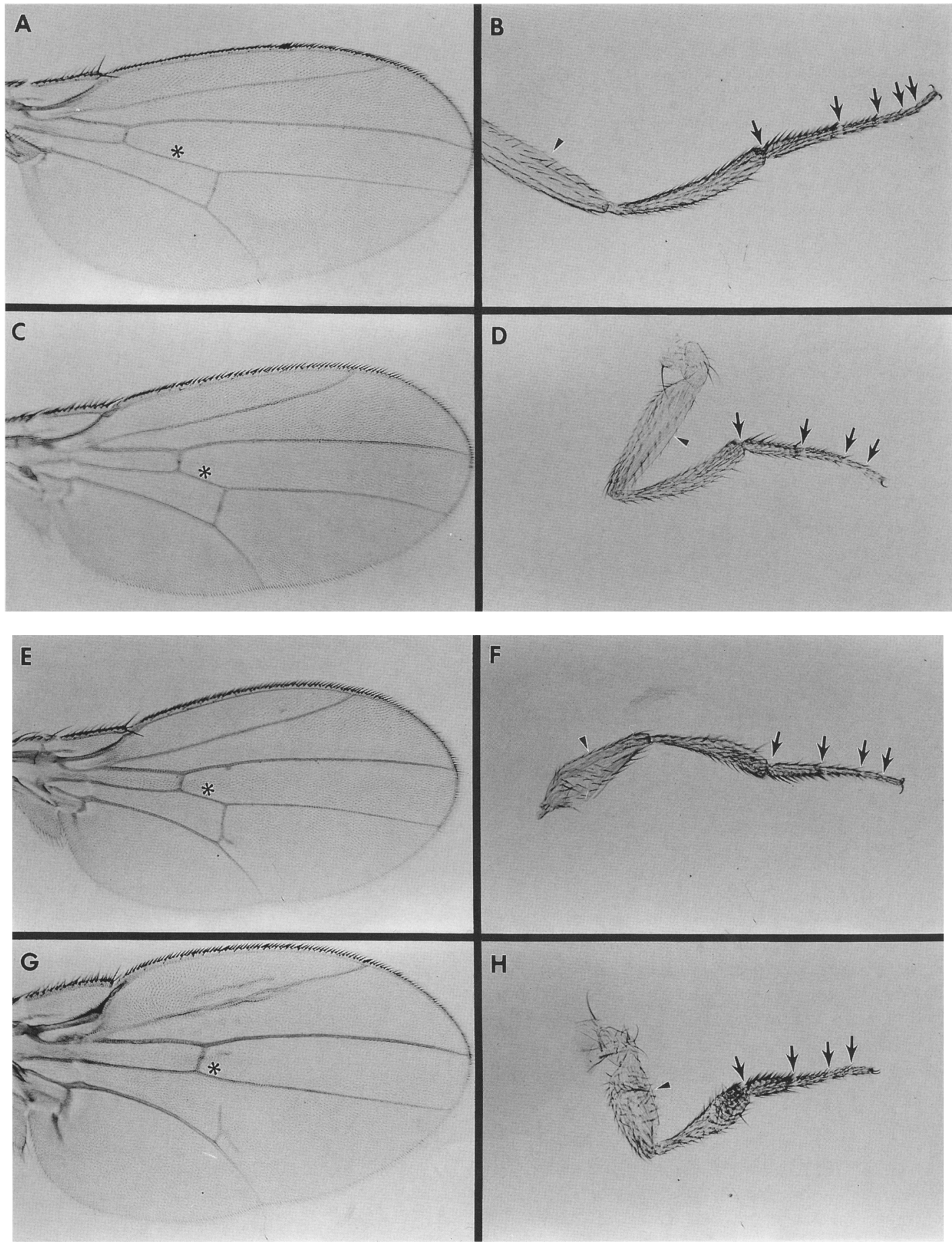

Figure 8. ds mutations cause defects in adult structures derived from imaginal discs. Examples of wing $(A, C, E, G)$ and leg $(B, D, F, H)$ phenotypes of wild-type Canton- $S$ flies $(A, B)$ are compared with those of the homozygous weak $d s^{1}$ allele $(C, D)$, the strong $d s^{38 k}$ allele $(G, H)$, and their transheterozygous combination of intermediate strength $(E, F)$. As the strength of the allelic combination increases, the distance between cross-veins (asterisks), the femur length (arrowheads), and the number of tarsal joints (arrows) are reduced.

A model for the interaction between $\mathrm{ds}$ and $\mathrm{ft}$

Two types of recessive $f t$ alleles are known. Viable $f t$ alleles display a morphogenetic phenotype similar to that of $d s$, whereas lethal $f t$ alleles produce hyperplastic overgrowth of imaginal discs. Gull is a dominant allele of $f t$ with respect to the morphogenetic phenotype but recessive with respect to the hyperplastic overgrowth 
phenotype. Moreover, the dominant effect of Gull is antimorphic or dominant negative (Mahoney et al. 1991) and, hence, results from an interaction and/or competition of mutant Gull protein with wild-type Ft protein, leading to an inhibition of $\mathrm{Ft}$ function (for review, see Herskowitz 1987|. The observation that this dominantnegative effect of Gull is partially suppressed by one and largely by two copies of $d s^{1}$ (Mohr 1929) favors a model in which both Ft and Gull are able to interact with Ds and $\mathrm{Ds}^{1}$ proteins, possibly through heterophilic interaction of their cadherin domains. It is also proposed that Ds and Ft interact in a homophilic fashion, suggesting the molecular model illustrated in Figure 9, which is consistent with the genetics of $d s$ and $f t$.

As argued above, $\mathrm{Ft}$ is proposed to mediate control of cell proliferation through its extracellular EGF-like and/ or its laminin A G-domain-like repeats, which probably interact as receptors with a membrane-bound or diffusible extracellular signal molecule. The Ds protein lacks these domains and thus is only able to modify this control, without disrupting it, through its homophilic and heterophilic interactions with itself and Ft. Because homozygous Gull larvae display the hyperplastic overgrowth phenotype of imaginal discs, Gull protein is unable to mediate the growth control signal and thus is presumably mutant in those Ft domains required for this control. Although the Gull mutation has been shown to be caused by the insertion of a 412 transposable element into the region encoding the thirty-third cadherin domain of $f t$ (Mahoney et al. 1991), its effect on the Gull protein is not known. In principle, the Gull product could consist of three not mutually exclusive mutant forms of the $\mathrm{Ft}$ protein: (1) a secreted, truncated protein consisting of 32 cadherin domains; (2) a transmembrane protein with extracellular EGF-like repeats, laminin A G-domain-like repeats, and less than two cadherin domains (Mahoney et al. 1991); and (3) a Ft protein from which a portion surrounding the site of the 412 insertion has been deleted because of the use of cryptic splice sites similar to what has been observed here for the $d s^{1} \mathrm{mu}$ tation (Fig. 4). That a truncated, secreted Gull protein causes the dominant mutation appears unlikely because very similar truncated, secreted Ft proteins do not exhibit a dominant effect (Mahoney et al. 1991). The two remaining possible forms of Gull are both membrane proteins, but only the third seems consistent with its suppression by $\mathrm{Ds}^{1}$ and its lack of growth control because it retains most cadherin domains and is mutant for the Fat-specific domains.

The dominant effect of Gull is explained by a heterophilic interaction of Gull with Ds that is stronger than that of $\mathrm{Ft}$ with Ds and thus reduces the number of homophilically interacting Ds proteins, resulting in a disturbed morphogenesis. The same effect is expected for $d s$ mutants, which explains their similar phenotype to that of heterozygous Gull mutants. Conversely, the suppression of Gull by $d s^{1}$ may be attributed to a decrease in strength of Gull-Ds ${ }^{1}$ as compared with Gull-Ds interaction, which leads to an increase in homophilically interacting $\mathrm{Ds}^{1}$ proteins and thus largely restores control

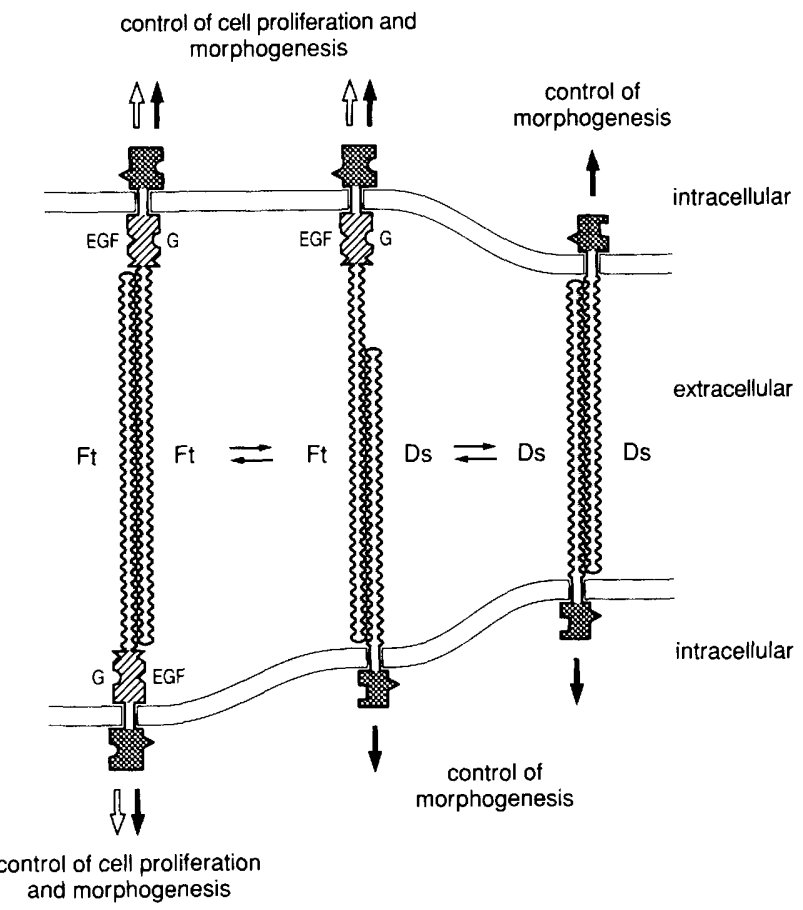

Figure 9. Model for role of Ds and Ft cadherins in control of morphogenesis and cell proliferation in imaginal discs. This model proposes that Ds and $\mathrm{Ft}$ mediate cell-cell adhesion by homo- and heterophilic interaction of their cadherin domains and transmit signals regulating morphogenesis and cell proliferation via their cytoplasmic domains to the cell interior and nucleus. It is possible that the extent of homo- or heterophilic association between cadherin domains can be modulated and is not maximal as illustrated here. The morphogenetic signals transmitted by Ds or Ft are not necessarily the same, although they might cooperate. Only $\mathrm{Ft}$, and not Ds, mediates signals controlling cell proliferation, through its specific extracellular EGF-like (EGF) and laminin A G-domain-like repeats (G) that act as receptors. Both processes, control of cell proliferation and morphogenesis, are intimately linked by coupled equilibria between homophilic and heterophilic associations of the Ds and Ft cadherins. For further details of this model, see text.

of morphogenesis. Thus, in this model, morphogenesis and cell proliferation are regulated by homophilic interactions of Ds and Ft proteins whose equilibria are coupled by heterophilic interactions between the two cadherin-like proteins. Accordingly, recessive viable mutations of $f t$, which show no loss of control of cell proliferation, are expected to affect the function of the $\mathrm{Ft}$ cadherin domains but not the Fat-specific domains and thus to shift the equilibria between Ft-Ft, Ft-Ds, and Ds-Ds interactions.

\section{Materials and methods}

\section{General procedures}

Standard procedures such as the isolation of genomic DNA, the construction and screening of genomic libraries, chromosomal walking, whole genome Southern analysis, in situ hybridization to salivary gland chromosomes, isolation and Northern analysis of poly $(\mathrm{A})^{+}$RNA, and PCR were carried out essentially as de- 
scribed (Frei et al. 1985; Kilchherr et al. 1986; Mahoney et al. 1991).

\section{DNA sequencing}

DNA sequences were determined on both strands of $d s$ cDNAs and the corresponding genomic DNA by the dideoxynucleotide method according to standard procedures or with a DNA sequencer model 373A using dye terminators (Applied Biosystems, Inc.).

\section{Isolation of cDNA clones}

Two embryonic Drosophila 9- to 12-hr cDNA libraries were screened (Zinn et al. 1988). One was prepared from oligo(dT)primed cDNA in $\lambda g t 11$, and the other from randomly primed cDNA in $\lambda$ ZAPII. The first $d s$ cDNA was obtained by screening the oligo(dT)-primed library with a subcloned PCR fragment. Subsequent overlapping cDNAs were obtained by "walking" through both libraries. No cDNA that derived from the 5 ' end of the $d s$ mRNA was found in the oligo(dT)-primed library, with the exception of some that were primed from a poly $(\mathrm{A})$ tract found in an intron of the $d s$ gene. About $50 d s$ cDNA clones were isolated from $8 \times 10^{5}$ phages.

Mapping of $\mathrm{ds}$ rearrangements and analysis of the $\mathrm{ds}^{1}$ mutation

The breakpoints of the inversions $d s^{33 k}$, associated with $\operatorname{In}(2 L R) b w^{V 1}$, and $d s^{55}$, associated with the SM5 balancer chromosome, of the translocation $T(2 ; 3) D^{4}$, and of the deficiencies $D f(2 L)$ ast 1 and $D f(2 L) S 2$ were mapped with respect to the chromosomal walk at $21 \mathrm{D} 1,2$ by in situ hybridization to salivary gland chromosomes and whole genome Southern analysis. The $d s^{1}$ mutation was characterized as RFLP by whole genome Southern analysis and isolated from a genomic library of homozygous $d s^{1}$ flies. To examine the mRNA products derived from $d s^{1}, d s^{1}$-cDNA was prepared by priming reverse transcription of poly $(\mathrm{A})^{+}$RNA from embryos or late third-instar larvae with the primer $5^{\prime}$-GGTAAATGTTGGGCGGTTGTC-3', located $0.46 \mathrm{~kb}$ downstream of the 412 insertion. These cDNAs were amplified by nested PCRs, using the additional primer 5'-CTGTGAATGTGTCCGAATCG-3', located $0.47 \mathrm{~kb}$ upstream of the 412 insertion, in the first PCR, and in the second PCR the primers $5^{\prime}$-GCCAGCGATCTGGACACGG-3' and 5'. CCACTACAAGGTCGTACAGC-3', located $0.42 \mathrm{~kb}$ upstream and $0.05 \mathrm{~kb}$ downstream of the 412 insertion, respectively. The various PCR products were cloned and sequenced (cf. Fig. 4).

In situ hybridization to whole-mount embryos and discs and immunostaining of embryos

In situ hybridization to whole-mount embryos and imaginal discs with digoxigenin (DIG)-labeled probes (Tautz and Pfeifle 1989) or immunostaining for $\beta$-galactosidase has been described previously (Li et al. 1993; Schneitz et al. 1993).

\section{Isolation and reversion of the P-element insertion $\mathrm{ds}^{2 \mathrm{D} 60 \mathrm{~b}}$}

The P-element enhancer trap line 2D60 was isolated by Dan Cimbora. To separate the $\mathrm{P}$ element inserted in $d s, 2 \mathrm{D} 60 \mathrm{~b}$, from a second insertion, 2D60a, the $2 \mathrm{D} 60$ chromosome was recombined with al $d p$ b pr c px sp, and $d s^{2 D 60 b} b$ pr c px sp recombinants were recovered.

The 2D60b P-element was excised by constructing a fly stock $d s^{2 D 60 b}$ b pr c px sp/CyO; ry ${ }^{506} / \mathrm{TM} 2$, ry and crossing these flies to $K i p^{p} \mathrm{P}\left[\mathrm{ry}^{+}, \Delta 2-3\right]$, a source of transposase, and selecting progeny that subsequently lost the $r y^{+}$marker carried by the P-element insertion $d s^{2060 b}$. To isolate these progeny, the $d s^{2 D 60 b}$ b pr c px sp/ ; ry $\mathrm{y}^{506} / \mathrm{Ki} \mathrm{p}^{p} \mathrm{P}\left[\mathrm{ry}^{+}, \Delta 2-3\right]$ or $d s^{2 D 60 b} \mathrm{~b} \mathrm{pr} \mathrm{c}$ $p x s p /+$; TM2, ry/Ki $p^{p} \mathrm{P}\left[r^{+}{ }^{+}, \Delta 2-3\right]$ male progeny were crossed individually to $\mathrm{ry}^{506}$ or $\mathrm{rf}^{10} \mathrm{ry} / \mathrm{TM} 2, \mathrm{ry}$ virgin females in 127 lines. Flies with rosy eyes could result from loss of the P-element 2D60b from the marked second chromosome or from two wild-type second chromosomes. To isolate only the P-element excisions, every ry" male from each of the 127 isolines was tested and the excision chromosome, if present, balanced by crossing individually with $d s^{M 213} / C y O, p r$ or $\operatorname{In}(2 L R) b w^{V 1}$, $d s^{33 k} / \mathrm{CyO}$, pr virgins.

\section{Drosophila strains}

Most stocks were obtained from the Bloomington Stock Center. Marya Postner of Eric Wieschaus' laboratory (Princeton University, NJ/ kindly provided the $d s$ alleles $F 31 B, M 56, M 114, M 116$, $M 121, M 208$, and M213, which resulted from a screen for halo mutations, in a $c n b w s p / C y O$ background. $T(2 ; 3) D^{4}$ was supplied by Michael Ashburner (Cambridge University, UK), and $d s^{48 k} / C y O ; m w h h$ by Antonio García-Bellido (Universidad Autónoma de Madrid, Spain).

\section{Acknowledgments}

We thank Zaida Traquina, Patrick Spielmann, and Natasha Deleay for technical assistance and Fritz Ochsenbein for the artwork. We are grateful to Paul Mahoney for help in the early phase of this project, to Dan Cimbora and Shige Sakonju for the $d s$ enhancer trap line and the rescue plasmid, to Marya Postner in Eric Wieschaus' laboratory for providing the ethylmethane sulfonate (EMS)-induced $d s$ alleles, and to Luis Garcia-Alonso, Tom Elkins, and Michael Ashburner for genetics advice. We thank Hans Noll for comments on the manuscript. This work has been supported by a National Institutes of Health (NIH) Genetics Predoctoral Traineeship and NIH grant 5R37 HD21294 to H.F.C., by grant 31-26652.89 from the Swiss National Science Foundation to M.N., and by the Kanton Zurich. C.S.G. is an investigator with the Howard Hughes Medical Institute.

The publication costs of this article were defrayed in part by payment of page charges. This article must therefore be hereby marked "advertisement" in accordance with 18 USC section 1734 solely to indicate this fact.

\section{Note}

The GenBank accession number for the $d s$ cDNA sequence is L08811

\section{References}

Amagai, M., V. Klaus-Kovtun, and J.R. Stanley. 1991. Autoantibodies against a novel epithelial cadherin in pemphigus vulgaris, a disease of cell adhesion. Cell 67: 869-877.

Bate, M. and A. Martinez-Arias. 1991. The embryonic origin of imaginal discs in Drosophila. Development 112: 755-761.

Bryant, P.J., B. Huettner, L.I. Held Jr., J. Ryerse, and J. Szidonya. 1988. Mutations at the fat locus interfere with cell proliferation control and epithelial morphogenesis in Drosophila. Dev. Biol. 129: 541-554.

Campos-Ortega, J.A. and V. Hartenstein. 1985. The embryonic development of Drosophila melanogaster. Springer-Verlag, New York.

Cohen, B., E.A. Wimmer, and S.M. Cohen. 1991. Early develop- 
ment of leg and wing primordia in the Drosophila embryo. Mech. Dev. 33: 229-240.

Craymer, L. 1980. New mutants-D. melanogaster. Dros. Inf. Serv. 55: 197-200.

Finnegan, D.J., G.M. Rubin, M.W. Young, and D.S. Hogness. 1978. Repeated gene families in Drosophila melanogaster. Cold Spring Harbor Symp. Quant. Biol. 42: 1053-1063.

Frei, E., S. Baumgartner, J.-E. Edström, and M. Noll. 1985. Cloning of the extra sex combs gene of Drosophila and its identification by P-element-mediated gene transfer. EMBO I. 4: 979-987.

Frixen, U.H., J. Behrens, M. Sachs, G. Eberle, B. Voss, A. Warda, D. Löchner, and W. Birchmeier. 1991. E-cadherin-mediated cell-cell adhesion prevents invasiveness of human carcinoma cells. $/$. Cell Biol. 113: 173-185.

Hatta, K., A. Nose, A. Nagafuchi, and M. Takeichi. 1988. Cloning and expression of cDNA encoding a neural calcium-dependent cell adhesion molecule: its identity in the cadherin gene family. I. Cell Biol. 106: 873-883.

Herskowitz, I. 1987. Functional inactivation of genes by dominant negative mutations. Nature 329: 219-222.

Kemler, R. 1993. From cadherins to catenins: cytoplasmic protein interactions and regulation of cell adhesion. Trends Genet. 9: 317-321.

Kilchherr, F., S. Baumgartner, D. Bopp, E. Frei, and M. Noll. 1986. Isolation of the paired gene of Drosophila and its spatial expression during early embryogenesis. Nature 321: 493-499.

Li, X. and M. Noll. 1994. Compatibility between enhancers and promoters determines the transcriptional specificity of gooseberry and gooseberry neuro in the Drosophila embryo. EMBO /. 13: 400-406.

Li, X., T. Gutjahr, and M. Noll. 1993. Separable regulatory elements mediate the establishment and maintenance of cell states by the Drosophila segment-polarity gene gooseberry. EMBO I. 12: 1427-1436.

Lindsley, D.L. and G.G. Zimm. 1992. The genome of Drosophila melanogaster. Academic Press, San Diego, CA.

Magee, A.I. and R.S. Buxton. 1991. Transmembrane molecular assemblies regulated by the greater cadherin family. Curr. Opin. Cell Biol. 3: 854-861.

Mahoney, P.A., U. Weber, P. Onofrechuk, H. Biessmann, P.J. Bryant, and C.S. Goodman. 1991. The fat tumor suppressor gene in Drosophila encodes a novel member of the cadherin gene superfamily. Cell 67: 853-868.

Mohr, O. 1923. Modifications of the sex-ratio through a sexlinked semi-lethal in Drosophila melanogaster (besides notes on an autosomal section deficiency). In Studia Men. deliana: Ad centesimum diem natalem Gregorii Mendelii a grata patria celebrandum, pp. 266-287. Apud Typos, Brünn, Czechoslovakia.

. 1929. Exaggeration and inhibition phenomena encountered in the analysis of an autosomal dominant. Z. Indukt. Abstammungs-Vererbungsl. 50: 113-200.

Nagafuchi, A. and M. Takeichi. 1989. Transmembrane control of cadherin-mediated cell adhesion: A $94 \mathrm{kDa}$ protein functionally associated with a specific region of the cytoplasmic domain of E-cadherin. Cell Regul. 1: 37-44.

Nagafuchi, A., Y. Shirayoshi, K. Okazaki, K. Yasuda, and M. Takeichi. 1987. Transformation of cell adhesion properties by exogenously introduced E-cadherin cDNA. Nature 329: 341-343.

Oda, H., T. Uemura, K. Shiomi, A. Nagafuchi, S. Tsukita, and M. Takeichi. 1993. Identification of a Drosophila homologue of $\alpha$-catenin and its association with the armadillo protein. J. Cell Biol. 121: 1133-1140.
Oda, H., T. Uemura, Y. Harada, Y. Iwai, and M. Takeichi. 1994. A Drosophila homolog of cadherin associated with Armadillo and essential for embryonic cell-cell adhesion. Dev. Biol. 165: 716-726.

Ozawa, M., J. Engel, and R. Kemler. 1990a. Single amino acid substitutions in one $\mathrm{Ca}^{2+}$ binding site of uvomorulin abolish the adhesive function. Cell 63: 1033-1038.

Ozawa, M., M. Ringwald, and R. Kemler. 1990b. Uvomorulincatenin complex formation is regulated by a specific domain in the cytoplasmic region of the cell adhesion molecule. Proc. Natl. Acad. Sci. 87: 4246-4250.

Patthy, L. 1992. A family of laminin-related proteins controlling ectodermal differentiation in Drosophila. FEBS Lett. 298: 182-184.

Peifer, M. 1993. The product of the Drosophila segment polarity gene armadillo is part of a multi-protein complex resembling the vertebrate adherens junction. I. Cell Sci. 105: 9931000 .

Peifer, M., S. Orsulic, D. Sweeton, and E. Wieschaus. 1993a. A role for the Drosophila segment polarity gene armadillo in cell adhesion and cytoskeletal integrity during oogenesis. Development 118: 1191-1207.

Peifer, M., S. Orsulic, L.-M. Pai, and I. Loureiro. 1993b. A model system for cell adhesion and signal transduction in Drosophila. Development (Suppl.) 163-176.

Ringwald, M., R. Schuh, D. Vestweber, H. Eistetter, F. Lottspeich, J. Engel, R. Dölz, F. Jähnig, J. Epplen, S. Mayer, C. Müller, and R. Kemler. 1987. The structure of cell adhesion molecule uvomorulin. Insights into the molecular mechanism of $\mathrm{Ca}^{2+}$-dependent cell adhesion. EMBO /. 6:36473653.

Schneitz, K., P. Spielmann, and M. Noll. 1993. Molecular genetics of aristaless, a prd-type homeo box gene involved in the morphogenesis of proximal and distal pattern elements in a subset of appendages in Drosophila. Genes \& Dev. 7: 114-129.

Shepherd, B.M. and D.J. Finnegan. 1984. Structure of circular copies of the 412 transposable element present in Drosophila melanogaster tissue culture cells, and isolation of a free 412 long terminal repeat. I. Mol. Biol. 180: 21-40.

Stern, C. and C.B. Bridges. 1926. The mutants of the extreme left end of the second chromosome of Drosophila melanogaster. Genetics 11: 503-530.

Takeichi, M. 1991. Cadherin cell adhesion receptors as a morphogenetic regulator. Science 251: 1451-1455.

Tautz, D. and C. Pfeifle. 1989. A non-radioactive in situ hybridization method for the localization of specific RNAs in Drosophila embryos reveals translational control of the segmentation gene hunchback. Chromosoma 98: 81-85.

Vleminckx, K., L. Vakaet Jr., M. Mareel, W. Fiers, and F. Van Roy. 1991. Genetic manipulation of E-cadherin expression by epithelial tumor cells reveals an invasion suppressor role. Cell 66: 107-119.

Waddington, C.H. 1943. The development of some "leg genes" in Drosophila. J. Genet. 45: 29-43.

Will, B.M., A.A. Bayev, and D.J. Finnegan. 1981. Nucleotide sequence of terminal repeats of 412 transposable elements of Drosophila melanogaster: A similarity to proviral long terminal repeats and its implications for the mechanism of transposition. /. Mol. Biol. 153: 897-915.

Wodarz, A., F. Grawe, and E. Knust. 1993. CRUMBS is involved in the control of apical protein targeting during Drosophila epithelial development. Mech. Dev. 44: 175-187.

Zinn, K., L. McAllister, and C.S. Goodman. 1988. Sequence analysis and neuronal expression of fasciclin I in grasshopper and Drosophila. Cell 53: 577-587. 


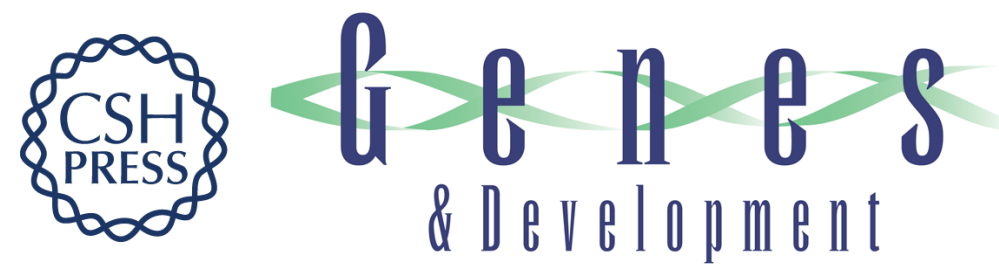

\section{Dachsous encodes a member of the cadherin superfamily that controls imaginal disc morphogenesis in Drosophila.}

H F Clark, D Brentrup, K Schneitz, et al.

Genes Dev. 1995, 9:

Access the most recent version at doi:10.1101/gad.9.12.1530

References This article cites 36 articles, 11 of which can be accessed free at:

http://genesdev.cshlp.org/content/9/12/1530.full.html\#ref-list-1

License

Email Alerting

Service

Receive free email alerts when new articles cite this article - sign up in the box at the top right corner of the article or click here.

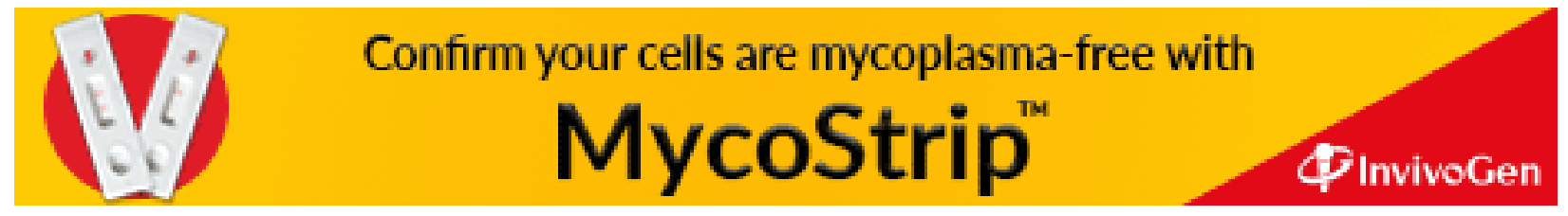

